\title{
Investigating the relationship between quality of life and mental health: A case study of steel industry
}

\author{
Ashraf al-Muluk Kamrani ${ }^{\mathbf{a}^{*}}$ and Abdullah Shafiabadi ${ }^{\mathrm{b}}$
}

\begin{abstract}
${ }^{a}$ Masters Student, Department of Counseling, Marvdasht Branch, Islamic Azad University, Marvdasht, Iran ${ }^{b}$ Department of Counseling, Allameh Tabatabaie University, Tehran, Iran

C H R O N I C L E

Article history:

Received July 28, 2013

Accepted 14 January 2014

Available online

March 62014

Keywords:

Quality of life

Mental Health

General Health

Esfahan Steel Company
\end{abstract}

\section{Introduction}

For years, there have been an ongoing debates on work conditions, quality of life, etc. and many suggest that quality of life could be influenced by various factors in work conditions. Quality-of-life assessment measures changes in physical, functional, mental, and social health to make an assessment on the human and financial expenses as well as advantages of new programs and interventions (Testa \& Simonson, 1996). Naughton and Wiklund (1993) performed a comprehensive review of dimension-specific measures of health-related quality of life in cross-cultural research. Quality of life assessment is increasingly applied in mental health. There are various instruments but the conditions for choosing one instrument over another for purposes of a specific study are not completely clear. We performed a systematic review to identify the QoL instruments used in mental health. Prigent et al. (2014) studied the existence of similar tools with respect to each of these sets of characteristics and investigated potential links between instruments' intrinsic properties and their characteristics of utilization. Brackbill et al. (2013) concentrated on different factors associated with subjective unmet mental health care need (UMHCN) and its association with a combination of diagnostic history and *Corresponding author

E-mail addresses: oooo5148@gmail.com (A. A. Kamrani) 
current mental health symptoms, 5-6 years after the 9-11-01 World Trade Center (WTC) disaster in New York City, USA. They reported important differences among enrollees who were categorized based on the presence or absence of a self-reported mental health diagnosis and symptoms indicative of post-traumatic stress disorder or serious psychological distress. People with diagnoses and symptoms maintained the highest levels of UMHCN, poor mental health days, and mental health service use. Miller et al. (2013) tried to explore the correlates of health-related quality of life (HRQOL) across treatment settings using baseline data from a multisite, randomized controlled trial for adults with bipolar disorder. Lev-Ran et al. (2012) evaluated mental health-related QoL among individuals with anxiety disorders with and without concurrent cannabis implementation based on a large representative US sample. The results highlighted the importance of taking into account direct functional and emotional outcomes, as well as frequency of cannabis used, when evaluating the effect of cannabis implementation among individuals with anxiety disorders. Subramaniam et al. (2013) attempted to establish and compare the QALY losses associated with select mental and chronic physical conditions in Singapore. They reported that pain conditions, hypertension and MDD were related to the highest loss of QALYs in Singapore at a population level.

\section{The proposed study}

This paper examines the relationship between quality of life and mental health among regular employee who work for Esfahan Steel Company, Iran. The study uses two questionnaires, one for measuring quality of life, which is adopted from Goldberg and Williams (2000). In addition, the study uses another questionnaire, which is adopted from Juniper et al. (1994). The sample size is calculated as follows,

$$
n=\frac{N \times z_{\alpha / 2}^{2} \times p \times q}{\varepsilon^{2} \times(N-1)+z_{\alpha / 2}^{2} \times p \times q},
$$

where $N$ is the population size, $p=1-q$ represents the yes/no categories, $z_{\alpha / 2}$ is CDF of normal distribution and finally $\varepsilon$ is the error term. Since we have $p=0.5, z_{\alpha / 2}=1.96$ and $N=5528$, the number of sample size is calculated as $n=150$. Fig. 1 shows details of some personal charactersitics of the participants who took part in our survey.

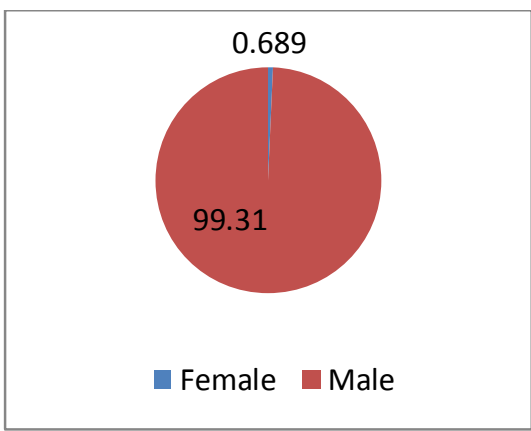

Gender

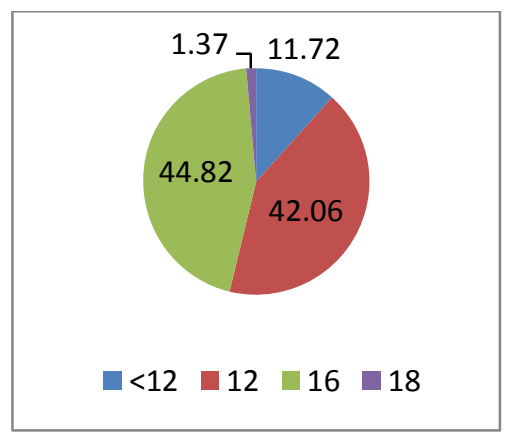

Years of education

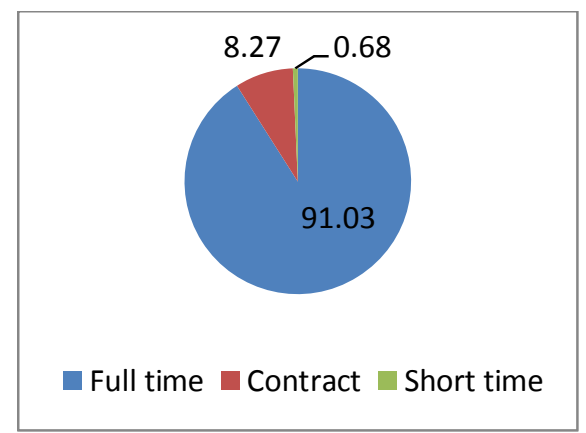

Employment

Fig. 1. Personal charactersitics of the participants

As we can observe from the results of Fig. 1, nearly half of the participants had some university education and nealy all of them were male and full time employees of this steel producer unit. Table 1 shows some statistics associated with different components of quality of life. 
Table 1

The results of mean and standard deviation of the questionnaire

\begin{tabular}{lccc}
\hline Variable & Mean & Standard deviation & Number \\
\hline Mental health & 19.88 & 11.52 & 108 \\
Quality of Work Life & 112.66 & 25.47 & 108 \\
Human Relations & 25.74 & 6.37 & 108 \\
Job security & 10.30 & 2.92 & 108 \\
Job progress & 9.8 & 5.711 & 108 \\
Working in partnership & 7.14 & 3.411 & 108 \\
Dignity & 7.12 & 3.76 & 108 \\
Balancing work and life & 15.76 & 2.92 & 108 \\
Work commitment & 24.17 & 6.14 & 108 \\
\hline Financial status & 12.55 & 6.37 & \\
\hline
\end{tabular}

\section{The results}

In this section, we present details of our statistical observations for the relationship between quality of life and mental health. First, we have performed Kolmogorov-Smirnov test and the result has confirmed that all data are normally distributed. Therefore, we use Pearson correlation ratio as well as stepwise regression technique to study the relationship between the quality of life and mental health. Table 2 shows details of correlation ratio between quality of life and its component with mental health.

\section{Table 2}

The results of the relationship between mental health and quality of life

\begin{tabular}{lccc}
\hline Variable & $\beta$ & Sig. & Result \\
\hline Quality of Work Life & -0.476 & 0.000 & Confirmed \\
Human Relations & -0.070 & 0.590 & Not confirmed \\
Job security & 0.137 & 0.114 & Not confirmed confirmed \\
Job progress & -0.126 & 0.398 & Not confirmed \\
Working in partnership & 0.012 & 0.931 & Not confirmed \\
Dignity & 0.017 & 0.904 & Not confirmed \\
Balancing work and life & 0.127 & 0.149 & Not confirmed \\
Work commitment & -0.208 & 0.169 & Not confirmed \\
\hline Financial status & 0.027 & 0.849 & \\
\hline
\end{tabular}

As we can observe from the results of Table 2, only quality of work life maintains meaningful relationship with mental health and other components do not represent any relationship with mental health. Table 3 shows details of ANOVA test for stepwise regression model.

Table 3

The results of stepwise regression technique

\begin{tabular}{lccccc}
\hline Model & Sum of Squares & $\mathrm{df}$ & Mean of Squares & F-value & Sig. \\
\hline Regression & 3218.78 & 1 & 3218.78 & 31.03 & 0.000 \\
Residual & 10993.87 & 106 & 103.716 & & \\
\hline Total & 14212.667 & 107 & & & \\
\hline
\end{tabular}

The results of Table 3 show that there is a meaningful relationship between mental health and quality of wok life. Table 4 shows details of regression analysis.

Table 4

The relationship between mental health and quality of work life

\begin{tabular}{lccccc}
\hline Model & Non-standard $\beta$ & Standard error & Standard $\beta$ & t-value & Sig. \\
\hline Intercept & 44.16 & 4.46 & -0.406 & 9.88 & 0.000 \\
Quality of work life & -0.215 & 0.039 & -0.476 & -5.57 & 0.000 \\
\hline $\mathrm{R}^{2}=0.476$ & & & &
\end{tabular}


As we can observe from the results of Table 4, there is a meaningful relationship between quality of work life and mental health. However, there seems to be no meaningful relationship between mental health and other quality of life components such as human relations, job security, job progress, working in partnership, dignity, balancing work and life, work commitment and financial status.

\section{Conclusion}

Steel industry plays essential role on development of economy and it is important to keep this industry efficient. Human resources play essential role on increasing the relative efficiency of this industry. In this paper, we have presented an empirical investigation to study the relationship between quality of life and mental health. The study has adopted two popular questionnaires for mental health and quality of life and using stepwise regression analysis, the study has determined some meaningful relationship between quality of work life and mental health. The results are somewhat consistent with findings Ronen (1981).

\section{Acknowledgement}

The authors would like to thank the anonymous referees for constructive comments on earlier version of this paper.

\section{References}

Brackbill, R. M., Stellman, S. D., Perlman, S. E., Walker, D. J., \& Farfel, M. R. (2013). Mental health of those directly exposed to the World Trade Center disaster: Unmet mental health care need, mental health treatment service use, and quality of life. Social Science \& Medicine, 81, 110-114.

Goldberg, D., \& Williams, P. (2000). General health questionnaire (GHQ). Swindon, Wiltshire, UK: NFER Nelson.

Juniper, E. F., Guyatt, G. H., Willan, A., \& Griffith, L. E. (1994). Determining a minimal important change in a disease-specific quality of life questionnaire. Journal of clinical epidemiology, 47(1), 81-87.

Lev-Ran, S., Le Foll, B., McKenzie, K., \& Rehm, J. (2012). Cannabis use and mental health-related quality of life among individuals with anxiety disorders. Journal of anxiety disorders, 26(8), 799810.

Miller, C. J., Abraham, K. M., Bajor, L. A., Lai, Z., Kim, H. M., Nord, K. M., ... \& Kilbourne, A. M. (2013). Quality of life among patients with bipolar disorder in primary care versus community mental health settings. Journal of affective disorders, 146(1), 100-105.

Naughton, M. J., \& Wiklund, I. (1993). A critical review of dimension-specific measures of healthrelated quality of life in cross-cultural research. Quality of life research, 2(6), 397-432.

Prigent, A., Simon, S., Durand-Zaleski, I., Leboyer, M., \& Chevreul, K. (2014). Quality of life instruments used in mental health research: Properties and utilization. Psychiatry research, 215(1), $1-8$.

Ronen, S. (1981). Flexible working hours: An innovation in the quality of work life. New York: McGraw-Hill.

Subramaniam, M., Abdin, E., Vaingankar, J. A., Nan, L., Heng, D., McCrone, P., \& Chong, S. A. (2013). Impact of psychiatric disorders and chronic physical conditions on health-related quality of life: Singapore Mental Health Study. Journal of affective disorders, 147(1), 325-330.

Testa, M. A., \& Simonson, D. C. (1996). Assessment of quality-of-life outcomes. New England Journal of Medicine, 334(13), 835-840. 